\title{
This Is The Hour: A Call for Reflection and Introspection in the Field of Mindfulness
}

\author{
Steven D. Hickman ${ }^{1,2,3}$
}

Published online: 17 September 2015

(C) Springer Science+Business Media New York 2015

I have become aware of an odd but familiar feeling arising in me recently. A feeling I am not proud of, even though at times I experience fleeting gratification alongside it. For nearly 16 years, I have been engaged in practicing mindfulness in my own life and also teaching it to others. I have the great privilege and honor of working with some incredibly talented and deeply wise professionals in our field and to play some role in the training of many more teachers over the years, as well as simply having the pleasure of forming connections and building friendships with some amazing mindfulness and compassion professionals across the globe.

It has taken me awhile to name the uneasy feeling, or even recognize it as problematic, but now that I see it more clearly I am feeling alarmed. Alarmed for the surreptitious way it crept into my passion for this work, and particularly alarmed for the field as a whole as I begin to recognize this trend wherever I go as I do this work.

What is this creeping scourge of the mindfulness community? What could possibly be infecting such a wholesome and heartfelt movement toward health, compassion, and well-being? It is actually an ancient tendency that has innocent enough roots: a tribal mentality.

What do I mean by a "tribal mentality"? I mean that feeling of "us" as a counterpoint to "them." Of course we might refer to this as the "myth of the separate self" or even just "selfing."

Steven D. Hickman

shickman@ucsd.edu

1 Department of Psychiatry, UC San Diego School of Medicine, La Jolla, CA, USA

2 Family Medicine \& Public Health, UC San Diego School of Medicine, La Jolla, CA, USA

3 UC San Diego Center for Mindfulness, San Diego, CA, USA
In our work it arises as it does in nearly all human endeavors, as a seemingly innocuous attitude toward a colleague who appears to be doing something not quite right, or a group that seems different in some way. But it is a slippery slope when noticing difference leads to subtle or not-so-subtle exclusion, or even aggression.

Let us say you are serving on a submission review committee for a mindfulness conference (as I have done on a few occasions), and although it is an anonymous submission, you recognize the work of a colleague in reading the abstract. You have found yourself doubting the "depth of personal practice" of that particular colleague (a sly way we mindfulness people have of differentiating ourselves from others and appearing to be entirely above reproach in commenting negatively upon one another). You find yourself reading the submission a bit more critically or instead mentally dismissing or discounting it regardless of the content. Might this simple act of "judgment" actually be what some call a "micro-aggression" with ultimately macro consequences?

And these small acts and attitudes begin to leak into other professional activities such that we begin to perceive patterns among certain other people, groups, or programs that just do not sit well with us. We smile and shake hands with these perceived transgressors (the other tribe) when we run into them at retreats or workshops, but we fail to copy them on invitations to collaborate or to invite them to our professional meetings. It is only a short trip from this exclusionary behavior to the somewhat shocking feuds between professional mindfulness groups (sometimes within the same country or community) that are currently well known and consistently maintained over time.

This is not to suggest that one should tolerate unskillful actions or attitudes when we encounter them in our colleagues. Instead we should be willing to "lean in" to the discomfort of gently inquiring when we encounter these potential 
sticking points, reaching out to explore and understand the other's views and attitudes and see if the issue can be resolved through genuine collaboration, consultation, or support. Sometimes this results in no beneficial resolution and perhaps a fiercely compassionate act can be limiting interactions with someone or some program or choosing not to recommend people or programs to others. But this should be done from a platform of clear seeing and careful consideration of the facts of the situation and not based on hearsay, fleeting impressions, or "stories" of things about which we hold little actual data.

We all have preferences, biases, predispositions, and longheld opinions about this work for which we hold such passion, but we, of all groups of people, have what I consider to be a sacred obligation to work with these views skillfully with an intention for good and the relief of suffering in the world. I know from personal experience that it can be very easy to fall into identifying with "my" tribe and dismissing the others. There is an odd endorphin rush that I get when I engage in a bit of wrong speech (i.e. gossip) that has to be evolutionary in nature. By identifying a distinct "other" I have more firmly established myself as belonging to the "herd" and thereby assured my survival in a way.

I admit that I am guilty of this, but I also learned most clearly of my guilt when I chose to watch my reactive mind and my tendency to exclude, and instead lean in closer with curiosity to something I could have easily avoided to maintain my pride and my view of "the world according to me." Several years ago, I was a peripheral party to a dispute between two of my mindfulness friends and colleagues (lets call them Bob and Ted), but primarily learned of it from Bob, with whom I had more regular contact. I was completely caught up in Bob's account of the dispute, which naturally cast Ted in a very negative light. I even had occasion to engage with Ted briefly via email to try and settle the dispute, which admittedly included some attempt on my part to chastise Ted for his apparent bad behavior. Not surprising with an agenda like that, little was gained by this tense discussion, and I let it go.

As history would have it, I recently had the opportunity to revisit the topic with Ted, now that I had a completely different perspective on Bob, having worked with him and learned of his style of working and relating. I came to realize that the "truth" of the dispute was not nearly so black and white, and I had acted (and reacted) based on no actual "data" from the situation. As I engaged with Ted, I worried that perhaps in my "tribalizing" of Bob versus Ted, I had caused some hurt or harm to Ted and sought to seek forgiveness and clarity from him. We had several great conversations and a great deal of healing happened for us, but also for Ted over the wounds he had suffered in the original interaction.
This experience reminded me of how much incidental "collateral damage" we can inflict unknowingly with the hearts and minds of our beloved and valued colleagues and friends. This is true for us as human beings in general, but as mindfulness teachers we need to maintain an even higher standard of care and awareness of bias, discrimination, selfing, and ethics in general.

My wife hears of some of the petty squabbling that goes on from time to time in our field and is appalled at "you mindfulness people" for acting in this immature and hurtful way. I am embarrassed to admit that this goes on, even though we do not hold ourselves up as being perfect, enlightened beings. But the absolute foundation of our work is clear seeing, equanimity, compassion, a desire to relieve suffering and a solid ethical foundation for what we do. If we cannot lead by example and embody what we teach, how can we ever hope to influence the people we teach, the teachers we train, the cultures we inhabit, or the world we hope to improve?

I was recently inspired by a quote that was attributed to a native American (Hopi) elder that I feel speaks eloquently to each of us doing the work of teaching mindfulness to others.

\section{A Hopi Elder Speaks}

You have been telling the people that this is the Eleventh Hour, now you must go back and tell the people that this is the Hour. And there are things to be considered. . .

Where are you living?

What are you doing?

What are your relationships?

Are you in right relation?

Where is your water?

Know your garden.

It is time to speak your Truth.

Create your community.

Be good to each other.

And do not look outside yourself for the leader.

Then he clasped his hands together, smiled, and said,

"This could be a good time!"

There is a river flowing now very fast. It is so great and swift that there are those who will be afraid. They will try to hold on to the shore. They will feel they are torn apart and will suffer greatly.

Know the river has its destination. The elders say we must let go of the shore, push off into the middle of the river, keep our eyes open, and our heads above water. And I say, see who is in there with you and celebrate. At this time in history, we are to take nothing personally, 
Least of all ourselves. For the moment that we do, our spiritual growth and journey comes to a halt.

The time for the lone wolf is over. Gather yourselves! Banish the word 'struggle' from you attitude and your vocabulary. All that we do now must be done in a sacred manner and in celebration.

We are the ones we've been waiting for.

The raging torrent of public attention to and enthusiasm for mindfulness is this wild river that threatens to wash us all away into infighting, bickering, and tribal warfare if we are not able "see who is in there with" us and to keep our heads above water and still swim in the stream of humanity with purpose, intention, and grace. It is time for each of us, individually and collectively, to look deeply into ourselves (and we have the skills to do this!) and see where we might let go of some tribal bias and bind ourselves to the best intentions and deep commitment of our colleagues in bringing mindfulness and compassion into a world that desperately needs it.

The real question becomes whether we can banish the word "struggle" from our attitude and vocabulatory, do what must be done in a sacred manner and in celebration. We are, indeed, the ones we have been waiting for.

Conflict of Interest The author declares that he has no competing interests. 